\title{
El caso Banchero, de Guillermo Thorndike: fuente impresa que explica el culto a Luis Banchero Rossi, santo secular, en Lima
}

\section{Harold Hernández Lefranc}

(iD) https://orcid.org/0000-0002-3968-9429

Universidad Nacional Mayor de San Marcos

hhernandezl@unmsm.edu.pe

Luis Banchero Rossi murió

En macabro salvajismo.

Hasta hoy nadie conoce A los verdaderos asesinos

Luis Banchero Rossi murió Siendo el más grande industrial.

Con su ingenio y su talento Al Perú le dio renombre.

A las empresas su ejemplo $Y$ al pescador su experiencia.

Luis Banchero Rossi, tu cuerpo se ha ido, pero ha quedado tu alma.

Ernesto Sánchez Fajardo, «El jilguero del Huascarán» (1928-1988)

Popular cantante de música vernacular ancashino

RESUMEN

La existencia del culto en el cementerio El Ángel a Luis Banchero Rossi - empresario peruano de la industria de pescado, asesinado en 1972- exige el interés por su génesis, dado que es un culto religioso a un personaje secular. El presente texto halla que esto es posible por dos razones: la muerte violenta produce santidad, y la sacralización no se restringe a los límites de la religión 
institucionalizada. Además, plantea que, en lo eficiente, un factor que explica el culto lo constituye el libro El caso Banchero (1973), del periodista y escritor Guillermo Thorndike. Además, practica una exégesis antropológica y evidencia rasgos mistificados y mesiánicos del personaje, su vida y su muerte, lo que se entiende como un antecedente del culto. Los cultos populares se difunden en lo fundamental a través de la oralidad, no por la palabra escrita; sin embargo, en este caso se desdibujan los límites entre la cultura popular y el texto escrito, cuyo intermediario es la prensa.

Palabras clave: Luis Banchero Rossi, cultos religiosos populares, santo secular, caso Banchero, Guillermo Thorndike.

\title{
El caso Banchero, of Guillermo Thorndike: Printed source that explains the cult to Luis Banchero Rossi, secular saint, in Lima
}

\author{
ABSTRACT
}

The existence of the cult to Luis Banchero Rossi-Peruvian businessman of the fish industry, who was murdered in 1972-, in the Angel cemetery, it demands the interest for its genesis, being that it is a religious cult to a secular character. The present text find that this is possible for two reasons: the violent death produce holiness; and the sacralization is not restricted to the limits of the institutionalized religion. Moreover, it proposes that, in the efficient, a factor that explains the cult is the book El caso Banchero (1973), of the journalist and writer Guillermo Thorndike. Furthermore, it practices an anthropological exegesis of it; and it evidences in this, mystified and messianic traits of the character, his life and his death; and they are understood like antecedents of the cult. Popular cults are disseminated fundamentally through of the orality, not by the written word; nevertheless, in this case the limits between the popular culture and the written text become blurred, which intermediary is the press.

Keywords: Luis Banchero Rossi, popular religious cults, secular saint, Banchero case, Guillermo Thorndike. 


\section{INTRODUCCIÓN}

La manifestación constitutiva de la religiosidad popular está compuesta por el culto a los santos, que se expresa en lo fundamental en una relación mística e íntima entre el devoto y la persona metafísica, es decir, alguna advocación de Cristo o de la virgen María, o bien una diversidad de santos. Pueden distinguirse tres tipos de santos desde la cualidad de la extensión de su culto: (i) los que pueden ser reconocidos por tradiciones religiosas locales o regionales promovidas o monitoreadas por iglesias locales; (ii) los que pueden ser reconocidos institucionalmente por la Iglesia católica a través de, actualmente, la Congregación para las Causas de los Santos, lo que supone un proceso burocrático extenso y complejo que exige una suma de condiciones formales que se prueban desde un proceso judicial; (iii) los que no son reconocidos institucionalmente por la Iglesia católica y prácticamente no tienen la posibilidad de aceptarse por la institución como tradiciones locales o regionales, dados orígenes y trayectos sociales que escapan de los parámetros y exigencias de la institución, en lo fundamental porque no hay evidencia ante la Iglesia católica de que el posible candidato haya vivido virtuosa y heroicamente su fe, o bien porque, antes de algún pretendido proceso eclesial de santidad, las manifestaciones populares de piedad se hayan apropiado del personaje y se le haya iniciado un culto reñido con las exigencias eclesiales formales. Un caso paradigmático en el Perú es el culto a Sarita Colonia.

Más aun, suele ser que, en algunos casos, estos santos populares hayan estado muy lejos de estas características de virtud y heroicidad de fe: en el caso peruano, por ejemplo, Udilberto Vásquez Bautista ( $† 1970)$, de Cajamarca, sentenciado por la justicia a fusilamiento por violación y asesinato de una niña, o Víctor Apaza Quispe († 1971), de Arequipa, sentenciado por la justica a fusilamiento, por uxoricidio (Leonardini y Borda, 1996; Leonardini, 2002). El eje de esta relación con estas personas metafísicas o preternaturales, a las cuales culturalmente se llama 
santos, es, en la experiencia subjetiva de las personas, el milagro, y su contrapartida, la promesa, dentro de una lógica de reciprocidad o intercambio de dones ${ }^{1}$.

Lo cierto es que el culto a Luis Banchero Rossi es particular, porque remite a un personaje público secular, connotado en la década de 1960. Es decir, este personaje en vida no estuvo vinculado ni se le vinculó a ninguna forma de religiosidad, ni institucional en su forma eclesiástica, ni popular en el sentido ritualista y de devoción a los santos. Más bien el personaje fue un empresario marcadamente exitoso, un hombre de mundo, de acción, y que empezaba a vincularse en los medios de comunicación con la posibilidad del liderazgo del Perú en la esfera política, voceado como posible presidente de la República. Así, la pregunta pertinente a este respecto, que debe responderse, es la siguiente: ¿por qué existe un espontáneo, pero continuado, culto religioso a un empresario pesquero, Luis Banchero Rossi, asesinado dramáticamente en 1972, durante un gobierno de facto, y se le pide milagros o favores como a un santo?

La respuesta que postulamos apunta a dos hechos constitutivos de la antropología de este culto, pero no se limita a este caso puntual, pues se advierten estos hechos también en otros espacios, por ejemplo, de América Latina: (i) la muerte violenta produce santidad, y (ii) los fenómenos de sacralización de las personas no se restringen a los límites de la religión en el sentido formal del concepto. Es precisamente desde el entendimiento de estas dos consideraciones como es posible comprender, a su vez, que un factor importante en la «santificación» de Banchero puede ser el discurso de un periodista y escritor, Guillermo Thorndike, concretado en El caso Banchero, publicado en abril de 1973, solo quince meses luego de su asesinato, y en cuya nota preliminar se lee lo siguiente: «Lo que aquí se cuenta no es ficción [...] Cualquier semejanza con personas vivas o muertas no es, por tanto, una casualidad». Pero antes de explicar los dos hechos de la antropología del culto y de leer El caso Banchero, conviene describir sucintamente las formas de este culto.

1 Puede verse, por ejemplo, en Marzal (1989), especialmente en el capítulo II, lo fundamental que es, en la religiosidad popular, este vínculo subjetivo con el santo en el caso de un espacio urbano popular y de origen migrante, como en una parroquia del distrito de El Agustino, en Lima, Perú. Marzal utiliza el concepto de «iglesia cultural» para referir, considerando los límites del catolicismo, la religiosidad popular. El autor asimila los conceptos de iglesia cultural, catolicismo popular, religión popular y piedad popular, «términos que para mí tienen el mismo significado» (1989, p. 185), dentro de un interés por circunscribir los cultos populares en el Perú al catolicismo, asunto que no es relevante desde la perspectiva del presente estudio y al parecer tampoco de los devotos de la diversidad de cultos populares en el Perú. 


\section{EL CULTO A LUIS BANCHERO ROSSI EN EL CEMENTERIO EL ÁNGEL DE LIMA}

Enterrado a su muerte, el 1 de enero de 1972, en el cementerio general El Ángel, en el distrito de El Agustino, Lima — fundado en 1959-, a los escasos años sus restos fueron trasladados en el interior del cementerio, a la avenida principal, en la acera derecha, a no más de cien metros de la entrada principal; es decir, accesible a los visitantes. Supone su tumba una extensión plana, cuadrangular, de lajas oscuras, de no más de $3 \mathrm{~m} \times 3 \mathrm{~m}$, que guarda un pequeño espacio en el área anterior para una planta ornamental. En el área posterior, una base rectangular representa un catafalco, en cuyo lado visible se lee Luis Banchero Rossi $\uparrow 1$-11972, y a su lado, una cruz de lajas claras elevada a no más de $3 \mathrm{~m}$ de alto. El espacio es marcadamente sobrio y austero. La amplia base es el espacio donde, todos los días del año, visitantes del cementerio ofrecen en lo fundamental flores y permanecen algunos minutos para orar y pedir eventualmente algún favor o conversar con él. No obstante, son los días 1 de noviembre (Día de los Muertos), y 1 de enero, día su muerte, cuando esta plataforma se repleta de flores.

Los entrevistados, desde las visitas hechas para con este informe, que frecuentan su tumba, no recuerdan con precisión cuándo sus restos se mudaron a este espacio, o bien solo han iniciado la relación con el difunto hace escasos años. Lo cierto es que esta mudanza a un espacio más accesible ha permitido la evidencia y extensión de este culto².

Entonces, el culto a Banchero consiste en que, todos los días, muchos de los deudos visitantes del cementerio, al pasar por su tumba, toman algunas de las flores destinadas a sus muertos y las depositan en la superficie referida. Algunos otros especialmente compran arreglos florales para el muerto y se detienen unos minutos ante él. Qué piensan, qué oran, qué piden, cómo conciben al muerto, qué relación comunicativa subjetiva tienen con él: en eso consiste el culto. Y

\footnotetext{
Sucede lo mismo, por ejemplo, con el culto de Salomé, en el Cementerio Central de Bogotá. De origen campesino, probablemente dedicada al meretricio, al menos leída así por mujeres dedicadas a este oficio que le piden favores cotidianamente, estaba enterrada en un espacio de enterramiento de sectores populares. Un devoto anónimo, hacia 1955, le agradeció un favor excepcional trasladando sus restos de ese espacio original al de los ex presidentes, más accesible y visible. Esto, según Peláez (2001) y Díaz Castellar (2015), hizo cundir su fama de hacer milagros, así como la extensión de este poder a otros personajes. Díaz Castellar insiste en que a esto se sumaron condiciones sociohistóricas muy precisas: pobreza, migración, violencia civil y política extendidas. Es de rescatar la idea de Peláez de que el culto a esta santa popular, como a otros que esta autora registra en el cementerio, se limita a un locus muy preciso: el cementerio. Sucede lo mismo con Banchero. Banchero es un culto de cementerio.
} 
esto lo referimos en lo que sigue desde once breves entrevistas a sus visitantes, hechas el 1 de noviembre de 2017 y el 1 de enero de 2018. Los once nacieron fuera de Lima: siete mujeres y cuatro hombres, que representan la relación entre varones y mujeres que visitan a Banchero. Todos tienen sesenta años o más; no obstante, la mayoría de ellos visitan la tumba acompañados de familiares, con hijos y nietos, quienes por imitación también echan flores a la tumba. Solo dos de ellos espontáneamente usaron la palabra «santito»; una de ellas, al preguntarle si era santo, me dijo que «no tanto como santo». Todos ellos le pedían, por salud, dinero, trabajo, su familia, sus hijos, pero especialmente por trabajo. Solo una usó la palabra «favor», ninguna usó la palabra «milagro». Todos «saben» que él los escucha y que puede interceder ante Dios por ellos.

La razón que esgrimen, extendida como caracterización: fue muy bueno, muy trabajador y muy generoso con sus trabajadores: «Fue un hombre trabajador»; «Ayudó a mucha gente»; «Dio mucho trabajo»; «Gente buena»; «Persona buena»; «Hombre justo»; «Fue bueno con sus trabajadores»; «Tranquilo, humilde, sencillo»; «Muy generoso con la gente del pueblo»; «Ha dado de comer a los pobres». Incluso tres de ellos espontáneamente me refieren que habría sido presidente si no lo hubieran matado. Y una persona más dice esto: «Él, sin ser presidente, colaboraba, invertía con la gente, con la gente humilde», sugiriendo que esos gestos o actos son los propios de un presidente: es decir, ser magnánimo y pródigo. Rasgos protopolíticos de la representación de su persona concretan en esta frase espontánea de una señora de sesenta años: «Si este hubiera llegado a la presidencia no habría pobres en el Perú». Otra mujer, de alrededor de sesenta años: «Ha sido un buen hombre, e incluso pudo haber sido presidente, pero lamentablemente lo mataron, ¿no? lo asesinaron». Otras dos personas más tienen esta visión, llamémosle, de utopía rota, de promesa que no fue, porque hubo intereses oscuros que decidieron su muerte. Aunque todos saben que fue asesinado, quienes abundan más en su muerte - que son cinco personas que lo refieren espontáneamente - entienden que en ella hay complot: «A las finales todo es turbio»; "Que un enclenque lo agarró y lo mató; ¿cree usted? que un hombre alto...». Las explicaciones: la mafia, Velasco, los rusos, se suman a posibles pistas sobre su mediática muerte. No hay velas, no hay fotografías, no hay placas, no hay estampas.

Debe decirse que los rasgos que caracterizan este culto están presentes como elementos de la persona de este santo secular en El caso Banchero, de Guillermo Thorndike, libro aparecido a escasos quince meses luego de su asesinato. No afirmo que los devotos asumieron el culto inspirados por esta crónica de su vida 
y muerte: afirmo que los rasgos proféticos y mesiánicos del personaje han sido creados o recreados por el escritor y han constituido parte del «mito Banchero», y que este se ha compartido a través de los medios de comunicación (prensa, radio, televisión): debe saberse que Thorndike era un periodista y escritor marcadamente activo en la década de 1970. Pero antes de entrar a la lectura de contenido del libro, es preciso dilucidar dos condiciones antropológicas que empujan a la santidad —además de muchas otras_ - referidas en lo que sigue.

\section{MUERTE VIOLENTA Y SACRALIZACIÓN FUERA DE LA RELIGIÓN}

\section{La muerte violenta produce santidad}

Banchero fue torturado y asesinado brutalmente; peor aún, la opinión pública nunca conoció las motivaciones exactas del asesinato. Hay amplia literatura que explica que la muerte violenta santifica, así como literatura que matiza esta interpretación. Veamos esto en el contexto de América Latina:

Chertudi y Newbery (1966-1967), quienes trabajaron un culto de la segunda mitad del siglo XIX, en la provincia de San Juan, en Argentina, la «difunta Correa», afirman lo siguiente: «En los grupos folk de nuestro país, las muertes ocurridas en circunstancias trágicas se consideran signadas con un sello divino [...] El hecho real es que, generalmente, una persona muerta en forma trágica recibe posteriormente un culto y surgen leyendas sobre su vida y milagros». Y observan que la vida de esta mujer fue absolutamente normal y anodina, en absoluto extraordinaria, de modo que esta no podía producir ningún mito, pero sí su muerte: «De su vida es difícil que surgiera una leyenda, pero de su muerte sí: tragedia, sufrimiento, milagros» (p. 125). Más adelante dicen que se cree que el alma de quien muere trágicamente adquiere poder, luego de un profundo padecimiento: «[...] está presente la idea de elevación y de purificación a través de un sufrimiento intenso [...]; tal sufrimiento purifica». Y agregan lo siguiente: «En la purificación está implícita la idea de purgatorio. El alma, así purificada por el sufrimiento intenso, se eleva a la santidad, pasa de lo profano a lo sagrado» (p. 128).

María Julia Carozzi (2005), casi treinta años después, hace una revisión crítica y severa de la explicación que ofrece el viejo texto de Chertudi y Newbery: critica la idea de que los santos populares acceden al carácter milagroso por haber sufrido muerte violenta o accidental dado el intenso sufrimiento, el cual purifica las almas y las hace intercesoras ante Dios (p. 14). Y postula alternativamente 
que la santificación puede suponer una actitud de resistencia a situaciones de dominación: o bien el milagro puede suponer un espacio utópico alternativo al orden real de lo social, o bien puede entenderse que con estas canonizaciones populares los creyentes podrían subvertir la fatalidad del orden establecido y solo usarían instrumentos comunicativos de la Iglesia, o este hecho sería evidencia de reclamos sociales no organizados o formulados muy explícitamente (pp. 14, 15). Además, esta autora rescata a Martín 2003 y 2004, así como a Freitas 2000, para sustentar sus postulados.

Martín $(2003,2004)$ se distancia también de la interpretación de que el santo popular es una constitución que copia de modo dependiente la ortodoxia del catolicismo. En Martín (2003), se critica una posición dualista, que atribuye a las personas un entendimiento de la realidad que establece fronteras muy institucionalizadas entre lo sagrado y lo profano, desde definiciones eclesiales. Así, la santificación de algunos personajes - es decir, la producción de santos populares-, desde esta perspectiva, que se critica, se lee como calco del modelo de canonización de la Iglesia, los milagros como expresión de santidad, los santos como mediadores entre los hombres y la divinidad, y la muerte en su función finalmente redentora. Martín (2004) trabaja algunas de las ideas de Martín(2003), pero desde un estudio puntual: el de los fans y devotos de Miriam Bianchi, Gilda, cantante de cumbia argentina marcadamente popular y carismática, muerta en un accidente carretero en 1996. Martín problematiza la muerte trágica como propiciadora de santidad: reconoce que hay amplia bibliografía que remite a la muerte inesperada, violenta o trágica como propiciadora de santidad y producción de milagros, pero que «[...] el caso de Gilda permite pensar en la posibilidad de una inscripción en lo sagrado previa al hecho de su fallecimiento» (2004, p. 110), y señala evidencia de que hay dos casos de supuesta cura milagrosa atribuida a ella cuando estaba en vida. Así, propone que no solo la muerte trágica inscribe a Gilda en una textura diferencial del mundo que la hace sagrada; así, puede haber otros procesos de «santificación», de inscripción en lo sagrado que no se reducen a la muerte trágica o a los milagros (Martín, 2004, p. 111).

Luego, si bien Carozzi (2005) afirma que Freitas 2000 dice que puede haber algo en la vida de los difuntos que preanuncia que a su muerte violenta se convertirían en milagrosos, y por tanto santos, y que sugiere «escenas santificadoras» en las vidas de difuntos que se suman a sus respectivas muertes violentas - cosa que debe aceptarse en el caso de Banchero-, Freitas (2007) desarrolla más ideas sobre los santos populares del Estado de Rio Grande del Norte que trabajó en su publicación de 2000: Jararaca $(† 1927)$, miembro de una banda armada, 
supuestamente enterrado vivo por la policía, y Baracho ( $† 1962)$, migrante pobre y analfabeto, asesino serial de taxistas, asesinado a su vez de dieciocho tiros en una ejecución sumaria extrajudicial por la policía. También insiste en la propia muerte violenta, a lo que se suma una característica en mi criterio fundamental: «de fuerte repercusión pública». Y afirma que, para la comprensión colectiva, esta parece ser «socialmente indigesta». Es decir, la muerte violenta de algún marginal o notable, que para el caso son lo mismo, y ventilada públicamente, a través de los medios de comunicación. Y que esto «[...] exigirá de la sociedad una reacción más fuerte en el sentido de elaborarla, de formular una respuesta simbólica y un tratamiento ritual para manejar la realidad que ella instaura [...]; es como si la muerte violenta, o disruptiva, fuese la muerte simbólicamente marcada, diferenciada y definida como tal en oposición a la muerte considerada normal y previsible» (2007, p. 67).

Así, hay muerte violenta, dramática, es decir, execrable, que puede ser interpretada no solo o no necesariamente como purgación de pecados y por tanto de santidad, sino como excepcionalidad que debe ser explicada ritualmente de modo especial.

\section{La sacralización no se restringe a los límites de la religión formal}

Sobre el asunto de los fenómenos de sacralización como no restringidos a los límites de la religión, Martín (2004), como se ha dicho más arriba, trabaja la relación de fans y devotos con Gilda. En términos etnográficos, la autora refiere que puede distinguirse entre fans y devotos a quienes tienen cercanía empática a su persona, que ella en todo caso no sería una santa in toto, o que si bien no es santa — para algunas personas —, cumple —en el sentido que hace milagros o favores - . Además, refiere un testimonio concreto valioso de un fan: «[...] fueron los medios los que empezaron con eso de que Gilda es milagrosa y los milagros de Gilda, ellos lo inventaron. Fue todo un invento de los medios» (p. 104).

Esto lleva a afirmar a Martín, analíticamente, que lo que se practica aquí es la exclusión de Gilda de la «religión», de modo que así se refuerza su carácter sagrado, y a concluir que existen relaciones con lo sagrado en grupos y prácticas no definidos propiamente como «religiosos» (2004, pp. 109, 112). Es decir, en la autora la idea es que «lo sagrado» no necesariamente aparece en el espacio institucionalizado y reconocido, por los actores sociales y por el investigador, de «la religión». Más adelante desarrolla la idea de que, al menos en algún culto (el de Gilda), puede suceder que el hacer milagros no sea potestad exclusiva de los santos, y por tanto no se limite a la esfera o ámbito de la religión; que es posible 
hablar de sacralización fuera de las relaciones devocionales y del discurso reconocidamente «religioso», y que religión y no religión no deben ser vistos como discontinuidad o ruptura, sino que la experiencia del milagro y de lo sagrado debe ser vista como dentro de un mundo subjetivo de continuidades discursivas y experienciales. Así, las fronteras entre categorías de seres milagrosos son abiertas y de tránsitos frecuentes (2007, pp. 31, 46, 48). Un sustento explicativo de Martín (2004) es Semán (2001): una de las claves para entender la religiosidad popular es observar que esta tiene una visión cosmológica, es decir, que en esta no hay una marcada distinción entre lo trascendente y lo inmanente, lo natural y lo sobrenatural; así, lo sagrado es solo un nivel más de la realidad, donde el milagro es parte de la cotidianeidad (2001, pp. 54, 55).

Luego, Pavez y Kraushaar (2010), enriquecen la discusión sobre las dos consideraciones (muerte violenta y sacralización, y sacralización no restringida a la religión) que explican cómo Banchero, que en vida fue perfectamente secular, es «santo» en el sentido de que se le piden favores y milagros. Critican la crítica de Carozzi y de Martín respecto de que la muerte violenta y dramática por sí misma decide la santidad y consecuentemente la capacidad milagrosa por alguna lectura que entienda que la muerte purga. Puntualmente refieren que: «[...] sería una ingenuidad intentar comprender la devoción popular sin considerar las "ideas" de santidad, ritos de devoción y testimonios de milagros, como "actos materiales definidos" a su vez, por el aparato ideológico material del que proceden las ideas de los sujetos [...]». Para ello, citan a Althusser y continúan con la frase siguiente: «El aparato ideológico en este caso es sin duda la Iglesia católica». Pero agregan luego en su argumento que esta moldura de la iglesia institucional no niega - y hay mucha evidencia de ello- que las manifestaciones populares religiosas pueden hacer caso omiso de concepciones ortodoxas; así, el milagro en la lectura popular evidencia una concepción teológico-política de estos sectores populares que no se restringe a los parámetros formales y eclesiales (Pavez y Kraushaar 2010, p. 450). Con esto vamos al siguiente tema: la no restricción de los límites de lo religioso para con la producción de santos: tener presente que ellos trabajan la santificación de una prostituta, Irene Iturra, «Botitas negras», en la ciudad minera chilena de Calama.

Afirman que la muerte violenta constituye la exigencia de un «acto trágico» que «engendra lo sagrado» sobre sujetos finalmente marginales o víctimas, y que esto puede combinarse con el modelo de santidad católica, que insiste en el martirio como culmen de una vida virtuosa. Así, muerte violenta y martirio pueden identificarse. Después de todo —afirman luego—, sacralizar («hacer 
sacro») supone sacrificio («dar muerte»); es decir, supone pasar de la vida a la muerte (Pavez y Kraushaar, 2010, pp. 451, 477). Todo esto tiene un valor o una función política: las canonizaciones populares recrean a personajes que cuestionan realidades; los santos corresponden a necesidades de cada época, vinculados con antagonismos de clase, raza y género, y refieren varios otros cultos. Rescatan el concepto de «significante flotante» de Lévi-Strauss (1971), y lo aplican a «Botitas negras».

Desde Lévi-Strauss, el universo se hace al hombre «significativo», lo cual no implica que necesariamente se desarrolle sobre él conocimiento, pero la potencia de la significatividad humana generó, digámoslo así, compulsivamente, identidad entre el significante y lo significado. Ahora bien, esa capacidad de producir significatividad que tiene el hombre hace que el universo tenga significado antes de que pueda saberse qué significa. Esto se vincula con el siguiente hecho: «[...] la existencia de una superabundancia de significante, en relación a los significados sobre los cuales ella puede posarse». Así, «[e]n su esfuerzo por comprender el mundo, el hombre dispone entonces siempre de un exceso de significación [...]» (1971, p. 40). Y líneas después refiere el concepto de «significante flotante», es decir, significaciones que eventualmente anclan en puntuales objetos o personas o entidades en general.

Con todo esto Lévi-Strauss refiere al hecho de que el hombre tiene una capacidad enorme de dar significatividad a las cosas, pero que esa significatividad no deviene necesariamente en conocimiento empírico de esas cosas, que los objetos sobre los que recae la significatividad pudieran ser arbitrarios, o mejor dicho, decididos socialmente, convencionalmente, y que las nociones de significatividad pueden no ser completamente conocidas, sino que pudieran tener «un valor indeterminado de significación» (1971, p. 37). Para lo que nos interesa, todo esto escapa o puede escapar del ámbito construido socialmente de la religión ya institucionalizada. Por eso, «Botitas negras» (y ese nombre es precisamente eso, un significante flotante, una metonimia de la persona que fue, y cuya biografía como hecho real y empírico es lo que menos interesa) se escapa de la construcción del espacio religioso institucionalizado, pero se integra a una construcción finalmente religiosa, que hace resistencia al sistema de clasificación hegemónico, de la forma «Iglesia». Por eso puede el personaje —o mejor, el significanteser sacado de un espacio no institucionalmente religioso, para construir desde la religión, finalmente, un espacio de demandas populares: se le pide por empleo en la mina, en la prostitución, suerte en los juegos de azar, justicia o castigo, sanación milagrosa, etcétera. 
Del breve registro etnográfico expuesto, y de los análisis y conceptualizaciones de diversos autores sobre otros santos populares en América Latina, puede explicarse la existencia del culto a Banchero. Es de notar que estos coinciden con la caracterización que tempranamente, casi inmediatamente luego de su muerte, hizo Thorndike (1973), como se leerá en el siguiente punto. Pero antes, en lo que sigue, esta caracterización.

Hay una relación con el personaje físicamente muerto, pero con quien se cree puede haber comunicación, concretada en el pedido de favores o milagros, aunque no se usen estas palabras. Se pide una intervención preternatural, pero se entiende que es factible, accesible y verosímil. Se cree que no solo su muerte es significativa — es decir, que sufrió alevosamente—, sino también su vida: fue excepcionalmente bueno, generoso, justo, magnánimo. Quienes lo visitan no explicitan el hecho de que es un personaje religioso o que están practicando un acto positivamente religioso; es decir, hay permeabilidad entre lo religioso y lo que no lo es, entre lo santo y lo que no lo es, entre la religión y lo que no lo es. El discurso que refiere que fue especialmente generoso con sus trabajadores, que daba trabajo a la gente que lo necesitaba y que era justo y magnánimo remite a una esfera utópica de carácter protopolítico, o casi político, con rasgos de crítica evidente a la realidad social y política presente.

En ese sentido, de manera evidente hay una resistencia a condiciones de dominación, un intento de subvertir la fatalidad del orden establecido, con la convicción de que puede ayudar en la vida, sumada al esfuerzo propio de la persona. Hay un execrar su muerte dramática y violenta, marcadamente publicitada por los medios, con rasgos de sospecha de complot de intereses malignos y poderosos. En ese sentido, hay una sutil lectura de su muerte como martirio. La muerte del personaje, en las representaciones, ha quebrado la promesa política de que pudiera haber sido presidente y acabado con la pobreza, pero ha abierto la posibilidad de que la promesa fuera religiosa, es decir, moral, espiritual. Banchero constituye, así, una suerte de «significante flotante», signo abierto y desbordante a la significación de la promesa de una mejor vida y un mejor trabajo.

\section{EL BANCHERO DE GUILLERMO THORNDIKE: EL CASO BANCHERO (1973)}

En el empresario Banchero, la construcción de su «santidad» está vinculada con características propias de su personalidad que, dimensionadas por los medios sociales de comunicación, configuraron lo que llamo el «mito Banchero». Uno de 
los factores más importantes y primeros en el tiempo es, a los pocos meses luego de su mediática muerte, la primera edición de El caso Banchero, del escritor y periodista Guillermo Thorndike. Barral hizo la primera edición en 1973; la primera edición peruana fue de 1980, y esta coincidió con el estreno del filme peruano Muerte de un magnate, que también contribuyó a su popularidad post mortem. La construcción del personaje, dueño de diversos medios de prensa con tirajes de nivel nacional, ya se había iniciado con su participación activa en los propios medios. Pero es su muerte la que desenvuelve el «mito Banchero», el cual supone aspectos que ya Thorndike había propuesto tempranamente en su publicación.

Planteo que El caso Banchero (1973 y otras diversas ediciones) sustenta el mito. Lo que en este segmento se presenta es el modo como Thorndike crea al personaje y lo alimenta con el dramatismo del abominable y pasmoso crimen, de modo que su muerte violenta constituye elemento fundamental del mito y del culto a este santo secular. Aquí, la lectura del Banchero de Thorndike : «Lo que aquí se cuenta no es una ficción. Nombres, lugares y acontecimientos son reales. Fueron reconstruidos por sus protagonistas [...]. Cualquier semejanza con personas vivas o muertas no es, por tanto, una casualidad» (1980, p. 9). Así reza parte del epígrafe del texto. No obstante, Thorndike es un creador, es decir, escribe una historia, produce finalmente una intuición sobre el personaje que ya se estaba construyendo oral y espontáneamente. Pero el lenguaje escrito tiene la particularidad de que, compactado, reproducible y multiplicado, se difunde más allá del lenguaje oral y excede los límites de la oralidad.

Banchero, en Thorndike, es el más fabuloso pionero que alumbró el Perú, el mejor de su tiempo, de la estirpe de Meiggs y Fitzcarrald. No parecía peruano, en el sentido en que distinguía la amistad de los negocios. No confiaba, ni creía, sino en sí mismo. Trabajaba hasta dieciocho horas diarias, parecía que nunca descansaba, no dormía. Decía que «si todos se propusieran modificar el mundo, si todos sacrificaran domingos, intereses y egoísmos, el planeta cambiaría en una

\footnotetext{
Puede ser pertinente comparar sistemáticamente la consideración de Thorndike sobre el personaje con la que José María Arguedas (El zorro de arriba y el zorro de abajo) tiene de él. Si bien la fuente de Thorndike es una crónica y la de Arguedas es una novela, en la que el personaje Braschi es evidentemente Banchero, es pertinente el contraste, considerando que, más allá del formato y el género, en ambos autores (Thorndike y Arguedas) hay una vocación poética y política de construir la realidad, concebida también esta de modo divergente. Además, debe considerarse una secuencia de fechas: Arguedas se suicidó en 1969, la primera edición de la novela de Arguedas se publicó en 1971, Banchero fue asesinado en 1972, la primera edición de la crónica de Thorndike fue en 1973 (Hernández Lefranc, 2019).
} 
generación» (Thorndike, 1980, p. 87). Luchaba contra la exasperante lentitud con que rodaba el mundo.

Siguiendo esta caracterización, veo aquí que lo distinguía una ética del trabajo férrea, finalmente un ascetismo al que, releyendo algunas ideas de M. Weber (1974), podría llamarse intramundano de talante irracional. No le interesaba el dinero; es más, lo despreciaba, y aun más a quienes lo codiciaban. Muerto, se le declaró héroe civil. De hecho, se decía que iba a ser presidente. Pero era para los cercanos algo mucho más que eso: era la imagen del padre.

Thorndike, para referirse al empresario y sus capacidades, dispone de un discurso providencialista e irracionalista: «Una voz nocturna, casi demoníaca, comandaba al Hombre a no rendirse» (1980, p. 227). O de un episodio en Hamburgo, el autor dice que «el Hombre parecía olfatear un fuego divino, que andaba como un poseso» (1980, p. 190). El escritor usa aquí, y decenas de veces, el término con el que en algunos espacios de sus empresas era conocido: el hombre. Pero el lenguaje escrito permite la inicial mayúscula. El autor usa siempre el Hombre: esto tiene connotaciones religiosas: puede remitir a la frase el Hijo del Hombre, del Evangelio, referido al Mesías.

Esto no es exagerado: siguiendo a Thorndike, para uno de sus colaboradores más cercanos, un hombre de mar del espacio popular, y prontuariado exdelincuente, «el Hombre tenía características divinas. Todo lo podía» (1980, p. 136). El Hombre daba oportunidad a ladrones y malhechores y ninguno reincidía en delitos: cambiaban su vida, de manera que miles lograban la felicidad gracias a su prodigalidad, su dinero y su organización. «Del Hombre se hablaba como de una lejana divinidad», dice el escritor (p. 250).

$\mathrm{Y}$ es que lo que le interesaba al empresario no era el dinero, sino crear, inspirado en una motivación que nadie lograba descubrir con certeza. De este modo, con un sentido de misión que no se sabía de dónde le venía, sus cercanos lo veían finalmente - abstraigo - como un redentor: otro hombre de mar dice que «cuando entró a trabajar para el Hombre, sintió que cuanto hubo de malo en su vida había concluido» (1980, p. 250). Y se suma la idea de que nadie podía destruirlo: sus barcos, los mejores; sus fábricas, las que ganaban más; nunca faltaba a nadie que comer; había atención médica; nadie tenía muchas ganas de hacer huelgas. Es decir, observo no solo redención sino estado paradisíaco: sus empresas eran enclaves de perfección y abundancia.

Esta abundancia con la cual se ligaba al empresario se expresa también en un lenguaje mítico y fabuloso: dado que Banchero decía - y lo refiere Thorndike también — que la pesca era muy simple, porque solo se cosechaba: «Me gusta el 
mar. No hay que arar o sembrar en él, sólo cosechar» (p. 70), y dado que en el verano en que fue asesinado (1972) aconteció un fenómeno El Niño (las aguas del mar calentaron y la anchoveta se retiró a aguas más frías, produciendo una crisis de producción severa), la gente decía «acaso los peces se marchaban tras él. La mágica anchoveta empezó a desaparecer del mar peruano» (pp. 378, 379). Y hace decir a un hombre de confianza del asesinado: «Hace dos semanas que no veo pescau. Será porque lo han matado al Hombre» (p. 378).

En otro segmento dice Thorndike, con retórica profética, usando futuro simple: «Dirán que no le bastan los peces del océano o que, acaso, los peces lo seguirán». En ese mismo párrafo: «Lo harán una leyenda». «Le dirán el Hombre, a secas» (p. 139). Esta idea de que mágicamente atraía el pescado y que a su muerte se lo llevó se registra en diversos documentos periodísticos. Por ejemplo, en la publicación Somos, del periódico El Comercio, del 2 de enero de 2016: «Pero sus fieles parecen creer también, que Banchero sí se llevó algo con él. Antes, en su tiempo, había pescado. Cuando falleció, se fueron los peces. Esto pasó por su muerte, esa es mi creencia. La idea es repetida más de una vez entre quienes lo visitan. La muerte de Banchero fue la muerte del mar» (Meneses Sala, 2016, p. 31).

Vinculado con esto, el autor dice en el mismo párrafo donde refiere al empresario en futuro simple, lo siguiente: «Habrán de seguirlo y a donde él llegue se alzarán ciudades políglotas que a su imagen y semejanza nunca parecerán dormir». Esto refiere en un sentido inmediato a que Banchero tenía el ideal dionisíaco moderno de producir infinitamente, siendo que el ideal es la ciudad, la urbe, la metrópoli, lugar donde parece que nunca se duerme, como supuestamente parecía suceder con Banchero. Pero Thorndike dibuja, más bien subrepticiamente, la imagen del fundador de ciudades que fue el personaje bíblico Caín, y cierta asimilación a una suerte de Babel conciliada y redimida: «ciudades políglotas». Es el Caín de cierta corriente gnóstica que el premio Nobel de Literatura, Hermann Hesse, dibujó en Demian [1919].

En el texto bíblico, inmediatamente luego del asesinato del hermano, Jehová puso a Caín una señal para que no lo mate cualquiera que lo encontrara; parte como errante, conoce a una mujer con la que engendra un hijo y funda una ciudad con el mismo nombre que el del hijo; Caín es fundador de ciudades (Génesis 4, 15-17). En la lectura gnóstica de Hesse sobre Caín, este es un héroe, un tipo audaz, con inteligencia, lo cual generaba miedo a los tímidos y mediocres: suele ser que los más resueltos han sido vistos como siniestros por los timoratos. «Yo pienso que Caín era un gran tipo y que le echaron toda esa historia encima sólo porque le tenían miedo», dice Demian, personaje fundamental de la novela de 
Hesse. Es el débil el que teme al fuerte. El más fuerte mató al más débil. Caín era noble; Abel, un cobarde. Caín es la voluntad de la naturaleza hacia el futuro, la novedad, lo individual; y por eso su descendencia es vista como extraña, peligrosa, mala, perversa. Pero solo es que tienen mayor conciencia de sí mismos; se han atrevido a dejar el redil, la manada, el rebaño, el espíritu gregario.

El estigma de Caín pudo haber existido desde un inicio, razón por la cual los timoratos le temían; quizá fuera algo en su mirada. Y este estigma se hereda. El protagonista de la ficción, el joven Sinclair, al experimentar un proceso de crisis de adolescencia, auxiliado por Demian, mayor que él, lo descubre en algún momento de su tierna vida y dice: «El estigma de Caín sobre mi frente». Supone superar el miedo por no reconocerse a sí mismo, despertar a la conciencian del poder de uno mismo y aceptarlo. Demian le dice alguna vez a Sinclair lo siguiente:

Los pocos que estaremos preparados seremos nosotros. Por eso estamos marcados, como estaba marcado Caín, para despertar miedo y odio y sacar a la humanidad de su idílica estrechez hacia lejanías de peligro. Todos los hombres que han influido en el curso de la humanidad fueron, sin excepción, capaces y eficaces porque estaban dispuestos a aceptar el destino. Lo mismo Moisés que Buda, Napoleón o Bismarck (Hesse, 2017, p. 166).

Pudiera leerse esta figura, psicológicamente, como un proceso de individuación, como el rompimiento respecto a la dependencia infantil del padre. Al inicio de la ficción, narrando el protagonista un hecho episódico, pero traumático para un preadolescente, dice que fue $«[\ldots]$ el primer resquebrajamiento de la divinidad del padre, el primer golpe a los pilares sobre los que había descansado mi niñez y que todo hombre tiene que destruir para poder ser él mismo» (Hesse, 2017, p. 28). Y en la novela aparece una figura femenina, erótica pero espiritual, llamada Frau Eva, madre de Demian, y a quien el adolescente protagonista llama «la madre de todas las criaturas».

Luis Banchero, adolescente, en Trujillo ya, conoce a su prima, Alicia Rossi de la Riva. Es ella quien, según Thorndike, ofrece lecturas y sugestiones al futuro empresario, entre ellas, Demian, de Hesse. Esta lectura, supuestamente, hizo que el futuro empresario guiara su vida hacia la creación sin miedos y sin dudas. Sentiría Luis que él también llevaba la marca de los hijos de Caín y que encauzara sus ansias de asir el futuro y retarlo. Y en este modelo, supuestamente, veía a su prima Alicia como una sublimada Frau Eva. A lo largo del texto de Thorndike se refieren los rasgos de personalidad de Luis de luchar contra la corriente, el denuedo, el vivir rápido, como evidencia del signo de los descendientes de Caín, y su voluntad 
como gobernada por el estigma. Dice el autor: «Lentamente emergió un hombre obsesionado por la acción, que no hacía suyas las cosas para deleitarse en la posesión sino para marcarlas como propias y abandonarlas sin una mirada» (p. 64).

Supuestamente sus primas le leen la mano: su vida sería dramáticamente corta. Y sigue el autor insistiendo en este furor por la acción: parecía correr de sí mismo. Esto se vincula con alguna forma de aprensión respecto del padre y extensivamente a su niñez: el sentirse portador del estigma de Caín lo hizo asumir conciencia de su adultez y de tener que romper muy tempranamente con las ataduras de la familia y la niñez y el lugar de origen, los cuales le quedaban muy estrechos. Se puede vincular con esto la frase de Hesse sobre el «resquebrajamiento de la divinidad del padre». Demian fue una novela inspiradora para muchas generaciones de jóvenes en muchas latitudes desde su publicación, en 1919. Además, Thorndike afirma que el connotado periodista de la época, Raúl Villarán, quien trabajó para Banchero, planteaba que el odio al dinero y a quienes lo codiciaban se vinculaba a una muy mala relación con el padre: «Su desprecio por el dinero acaso provenía de la avaricia paterna, que lo hirió tan ferozmente durante su infancia en Tacna» (pp. 359, 360). Pero el escritor complementa esta configuración de su relación paterna con esta frase: «Cortaba la conversación si le hablaban de su padre. Ella [Silvia Iladoy, amiga íntima y confidente] preguntó una vez la razón: "Porque era pequeño", repuso sin vacilar» (p. 26). Su emigración de Tacna a Trujillo para estudiar ingeniería supuso esa liberación de la adolescencia y las ataduras del pasado.

El caso Banchero usa sistemáticamente un lenguaje mítico y profético vinculado con esto de vivir rápidamente y morir joven. Hay un segmento en que supuestamente dice que, si moría temprano, debería ser con estrépito y luego de haber vivido intensamente, de haber marcado la tierra con las uñas $y$, habiendo trascendido, conocerán su ausencia. Y se agrega lo siguiente: «"Me harán un vals como a Lucy Smith", dirá Banchero, “y lo bailarán los pescadores en los burdeles de Chimbote"» (p. 65). Esto dataría de inicios de la década de 1950-. Explico: se trata de un vaticinium post eventum interesante: Lucy Smith fue una conocida cantante nacida en Bolivia en 1924, migrada muy tempranamente al Perú, que murió trágica y misteriosamente en el Año Nuevo de 1950, justamente un 1 de enero, como Banchero, veintidós años después. Muy prontamente un compositor de valses, Abelardo Carmona, compuso el vals Lucy Smith, que perennizó a la jovencísima artista muerta extrañamente; a ese vals se refería supuestamente Banchero. ¿Premonición? Pero a Banchero no le compusieron y cantaron un vals, sino un huayno, Luis Banchero Rossi. Fue el ancashino - el puerto de Chimbote está en la región Ancash- Ernesto Sánchez Fajardo (1928-1988), «el jilguero 
del Huascarán», el compositor, representante de la Asamblea Constituyente de 1978. Fue el primer artista folklórico de origen andino que ocupó la alta magistratura de congresista, y su obra musical fue declarada Patrimonio Cultural de la Nación en 1988.

No solo su vida tuvo un sentido de necesidad, de carácter providencial: también su muerte. Esta fue fruto de un complot misterioso que nunca fue revelado: hubo un verdugo, fue traicionado, tuvo un carácter sacrificial. Pero ya había signos de animadversión contra él: fuerzas o intereses oscuros, como oscuros eran los trajes de los tres extraños que salieron de la casa de campo luego del asesinato, según una de las versiones de Juan Vilca, el hijo del jardinero, y que el escritor rescata. Thorndike pregunta por el responsable del crimen: ¿Juan Vilca? ¿Eugenia Sessarego? ¿El gobierno? ¿Los apristas? ¿El MIR? ¿La mafia? ¿La Cosa Nostra? ¿El SINAMOS? ¿El Servicio de Inteligencia? ¿Los nazis?

Se ha mencionado anteriormente el uso del futuro simple. Se trata de un recurso convencional en El caso Banchero y remite a la estrategia discursiva de los libros proféticos del Antiguo Testamento, así como en los Evangelios. Hay especialmente un párrafo en Thorndike, en la página 139, que evidencia palmariamente este recurso, remitiendo a una configuración providencialista y mesiánica del personaje. Aquí segmentos:

Dirán que no le bastarán los peces del océano o que, acaso, los peces lo seguirán. Dirán que es adversario peligroso [...] habrán de seguirlo y adonde él llegue se alzarán ciudades políglotas que a su imagen y semejanza nunca parecerán dormir. Dirán [...] que nadie puede ganar tanto dinero por las buenas [...] Dirán que es un gran capitán, que por él no se adueñaron los extranjeros de la industria. Dirán que sus riquezas no pueden siquiera imaginarse, que es dueño de todo y de todos. Lo harán una leyenda. Le dirán el Hombre a secas. Lo atacarán violentamente. Lo adularán. Sospecharán de él [...] Y habrá épocas, antes y después de Luis Banchero Rossi [...] lo inventarán como él, ahora, empieza a fabricarse (Thorndike, 1980, p. 139).

En este párrafo, completo, de 234 palabras, aparece el futuro simple «dirán» diez veces y veinticuatro veces algún verbo en futuro simple. Pero además hay otro recurso, vinculado con una estrategia retórica propia de textos mesiánicos, que solo señalo: al héroe se le abomina y se le ensalza. Se le execra y se le sacraliza, contradictoriamente y al mismo tiempo: en realidad, todo lo que se dice o hace es una de las dos cosas: violencia y adulación, dentro de un discurso evidentemente mítico y ritual. No dejamos de notar, además, el «antes y después» de Banchero, es decir, el parteaguas entre dos épocas, como un antes y un después de Cristo. 
Luego, todo el proceso de su muerte tiene un carácter no solo trágico, sino también dramático. Todo el libro es un contrapunto entre dos momentos: el pasado distante de la biografía del héroe desde niño y el tiempo de un cronómetro que cuenta las últimas horas de su vida: «faltaban 200 horas; faltaban 45 horas y 55 minutos, faltaban 880 segundos». Especialmente dramático es el segmento en que se narra la versión que remite a la traición:

Cuando fueron convocados para asesinar al Hombre les pareció imposible... el verdugo sonrió: Luis Banchero Rossi no saldría con vida... [Banchero] reconoció al que bajaba por la escalera con lentitud. Comprendió la magnitud de la traición... Una puñalada no era suficiente. Volvieron a clavarlo, pero el manodoble se detuvo a la mitad... La hoja hirió por segunda vez el pulmón... el verdugo conocía. Empuñó el mango salpicado, removió el cuchillo mientras su víctima temblaba violentamente, decolorado por aquel torbellino que destrozaba sus entrañas. Sin sacar el arma terminó de hundirla... [La víctima] volvió a mugir y a sacudirse [...] Y murió el niño ensortijado que jugaba en las calles de Tacna. Murió el que consolaba a Fiorentina [su madre]. Murió el que preguntaba por el mundo. Murió Lulo Banchero (Thorndike, 1980, pp. 282-283).

El dramático y sangriento momento que narra el autor hace que un eventual lector del ejemplar que leo, extraído de la biblioteca de la PUCP, en un rapto de execración contra los eventuales asesinos, anote una suerte de escolio en la parte inferior de la página 283: «hijos de puta». Si muchos años luego de su muerte el lector anónimo manifiesta su repudio contra los asesinos, puede entenderse lo que la opinión pública experimentó en 1972: «El asesinato de Luis Banchero Rossi sacudió al país de arriba abajo»; «Sepultado Banchero, la víctima, la sociedad quedaba ofendida por el asesinato» (p. 390).

Thorndike explicitaba también ya en 1973 la hipótesis nazi del asesinato de Banchero: en resumen, Klaus Barbie, criminal de guerra nazi, vinculado con la Gestapo, había llegado al Perú subrepticiamente huyendo de Europa bajo el nombre falso de Klaus Altmann, había adquirido una propiedad cerca de la casa de campo del empresario, tenía como amigo y socio en sórdidos negocios de extorsión a otro nazi de las SS, Federico Schwend, ambos presumiblemente con vínculos oscuros con la Policía de Investigaciones del Perú (PIP). El periodista alemán que trabajaba desde hacía años para Banchero, Herbert John, había acusado a Barbie y Schwend de extorsionar y asesinar al empresario. La cazadora de nazis Beate Klarsfeld había desenmascarado a Barbie, quien al verse descubierto fugó a Bolivia gracias a la ayuda del Ministerio del Interior del Perú. 
En abril de 1972, el juez instructor José Santos Chichizola había allanado la casa del ex nazi Schwend, también relativamente cerca de la casa de Banchero. Había encontrado papeles comprometedores, tráfico de divisas y de piezas arqueológicas, etcétera, pero ninguna evidencia de vínculo con el asesinato de Banchero. Todo esto constituía noticia en los medios del año 1972 y se rememora o ventila cada cierto tiempo, hasta el presente.

\section{COROLARIO}

Sonia Goldenberg, periodista y documentalista, escribió en 2017 un reporte sobre la visita de Emmanuel Macron — quien aún no había sido elegido presidente de Francia - al Memorial del Holocausto en el barrio Le Marais, de Paris, donde acudió el hijo de Beate Klarsfeld. Aquello de lo que trata la periodista es de una nota del Memorial en que se afirma la vinculación de Schwend, secuaz de Barbie, en el asesinato de Banchero, y que reaviva la teoría de la conspiración nazi. Goldenberg dice de Banchero lo siguiente: que este, siendo el hombre más rico del Perú, tuvo las agallas como para denunciar a Barbie y que eso merece un reconocimiento especial, y termina diciendo: «No puedo dejar de preguntarme cuál podría haber sido el destino del Perú si el empresario más talentoso, visionario y valiente que tuvimos no hubiera sido asesinado en el fatídico Año Nuevo de 1972» (Goldenberg, 2017). Quizá la respuesta pudiera ser la que me dio la señora anónima de unos sesenta años ante su tumba durante mi trabajo de campo, el 1 de noviembre de 2017, y que refiero más arriba: «Si este hubiera llegado a la presidencia, no habría pobres en el Perú».

Sobre esto último, fundamental para entender la santidad de este personaje, debe decirse que lo que empieza a dibujar Thorndike es la figura del héroe que no fue, del elegido por alguna suerte de providencia para que en último término guiara el destino del Perú, pero que por algún sino fatal no fue. Es decir, aquello que supuestamente el empresario desarrolló para con sus empresas y sus trabajadores - redención moral a través del trabajo y estado paradisíaco con la abundancia de la producción de la organización - hubiera podido replicarse en todo el Perú. En los periodistas ilustrados Thorndike y Goldenberg solo aparece como pregunta y con ciertos atisbos de entusiasmo y de tácito o explícito elogio; en la visitante anónima del cementerio, como en el resto de fieles que le rezan, le oran y le piden milagros, hay afirmación firme: si no lo hubieran matado, hubiera sido presidente del Perú y hubiera desaparecido la pobreza. Es la imagen de la promesa que no fue, de la utopía rota, del programa político-económico del Perú 
que no será, porque el héroe fue asesinado por intereses perversos y soterrados, por un complot, dentro de alguna causalidad diabólica inextricable, misteriosa.

Así, analíticamente se observa que la alternativa a la promesa rota, que no concretará en la historia, se traslada al cielo, que es lo mismo que la vida moral, para que el héroe, en su vida post mortem, termine su obra, con cada uno de los que le rezan, así como cumplía con sus trabajadores en vida. Este hecho de trasladar la posibilidad histórica real incumplida a — mistificadamente - los cielos, la moral y la fe íntima de los fieles, a través del martirio, del sacrificio cruento, de la víctima inocente, es el mecanismo fundamental que construye la santidad de Banchero.

\section{REFERENCIAS}

Carozzi, María Julia (2005). Revisitando la Difunta Correa: nuevas perspectivas en el estudio de las canonizaciones populares en el Cono Sur de América. Revista de Investigaciones folklóricas, 20, 13-21. Recuperado de http://www.diversidadreligiosa.com.ar/wp-content/uploads/2013/04/Carozzi_Difunta_Correa.pdf

Chertudi, Susana y Sara Josefina Newbery (1966-1967). La difunta Correa. Cuadernos del Instituto Nacional de Antropología, 6. Buenos Aires: Secretaría de Estado de Cultura y Educación. Recuperado de http://revistas.inapl.gob.ar/index.php/ cuadernos/article/view/340/113

Díaz Castellar, Daniela (2015). Origen y evolución de los ritos a los santos populares del Cementerio Central de Bogotá (trabajo de grado). Pontificia Universidad Javeriana, Facultad de Sociología, Colombia.

Freitas, Eliane Tania (2000). Violência e sagrado: O que no criminoso anuncia o santo? Ciencias Sociales y Religión / Ciências Sociais e Religião, 2, 191-203. Recuperado de https://seer.ufrgs.br/CienciasSociaiseReligiao/article/view/2166/854

Freitas, Eliane Tania (2007). ¿Cómo nace un santo en el cementerio? Muerte, memoria e historia en el nordeste de Brasil. Ciencias Sociales y Religión /Ciências Sociais e Religião, 9, 59-90. Recuperado de http://seer.ufrgs.br/index.php/CienciasSociaiseReligiao/article/view/2512/1155

Goldenberg, Sonia (2017). Macron hace memoria. Caretas. Lima, jueves 18 de mayo, 2017. Recuperado de http://caretas.pe/internacional/79070-macron_hace_ memoria

Hernández Lefranc, Harold (2019). El Banchero-Braschi de El zorro de arriba y el zorro de abajo, de José María Arguedas. Fuente para entender un culto secular. Investigaciones Sociales, 22(41), 57-68. Recuperado de https://revistasinvestigacion. unmsm.edu.pe/index.php/sociales/article/view/16757/14306 
Hesse, Hermann [1919] (2017) Demian. Historia de la juventud de Emil Sinclair. Madrid: Alianza Editorial.

Leonardini, Nanda y Patricia Borda (1996). Diccionario iconográfico religioso peruano. Lima: Rubican.

Leonardini, Nanda (2002). Una muerte sacralizada. Escritura y Pensamiento, 9, 73-81.

Lévi-Strauss, Claude (1971). Introducción a la obra de Marcel Mauss. En Marcel Mauss, Sociología y Antropología. Madrid: Tecnos.

Martín, Eloísa (2003). «Religiosidad popular»: revisando un concepto problemático a partir de la bibliografía argentina. Estudios sobre Religión 15, 2-9. Recuperado de http://www.acsrm.org/upload/newsletterantiguos/News15.pdf

Martín, Eloísa (2004). No me arrepiento de este amor. Fans y devotos de Gilda, una cantante argentina. Ciencias Sociales y Religión /Ciências Sociais e Religião, 6, 101-115. Recuperado de http://www.seer.ufrgs.br/index.php/CienciasSociaiseReligiao/article/view/2268/973

Martín, Eloísa (2007). Gilda, el ángel de la cumbia. Prácticas de sacralización de una cantante argentina. Religião e Sociedade, 27(2), 30-54. Recuperado de http:// www.scielo.br/pdf/rs/v27n2/v27n2a03>

Marzal, Manuel (1988). Los caminos religiosos de los inmigrantes de la Gran Lima. Lima: PUCP.

Meneses Sala, Daniela (2016). El empresario y los fieles. Somos, 1517. Lima, año XXIX, 28-32.

Pavez Ojeda, Jorge y Lilith Kraushaar H (2010). Nombre, muerte y santificación de una prostituta. Escritura y culto de botitas negras. Revista de Antropología Americana, 5(3), 447-492. Recuperado de http:/www.redalyc.org/html/623/62319341005/

Peláez, Gloria Inés (2001). Un encuentro con las ánimas; santos y héroes impugnadores de normas. Revista Colombiana de Antropología. Bogotá, 2001, 37, 24-41. Recuperado de http://www.redalyc.org/pdf/1050/105015287002.pdf

Semán, Pablo (2001). Cosmológica, holista y relacional: una corriente de la religiosidad popular contemporánea. Ciencias Sociales y Religión /Ciências Sociais e Religião, 3, 45-174. Recuperado de http://www.seer.ufrgs.br/index.php/CienciasSociaiseReligiao/article/view/2169/895

Thorndike, Guillermo (1980[1973]). El caso Banchero. Lima: Barral.

Weber, Max (1974). La ética protestante y el espíritu de capitalismo. Buenos Aires: Diez. 